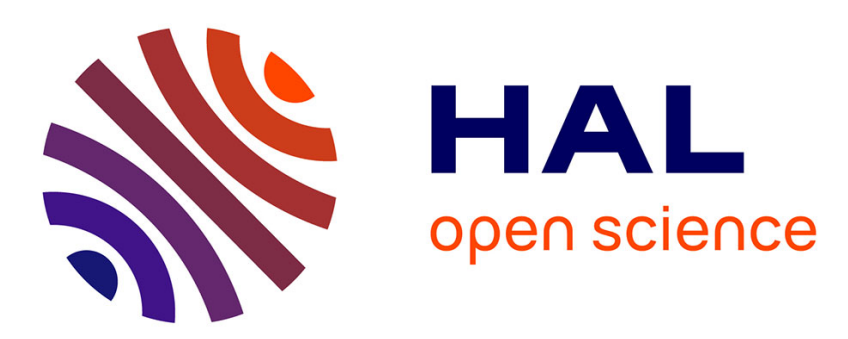

\title{
Ambient Humidity Influence on CO Detection with SnO 2 Gas Sensing Materials. A Combined DRIFTS/DFT Investigation
}

Susanne Wicker, Mathilde Guiltat, Udo Weimar, Anne Hémeryck, Nicolae Barsan

\section{To cite this version:}

Susanne Wicker, Mathilde Guiltat, Udo Weimar, Anne Hémeryck, Nicolae Barsan. Ambient Humidity Influence on CO Detection with SnO 2 Gas Sensing Materials. A Combined DRIFTS/DFT Investigation. Journal of Physical Chemistry C, 2017, 121 (45), pp.25064-25073. 10.1021/acs.jpcc.7b06253 . hal-01685597

\section{HAL Id: hal-01685597 https://hal.science/hal-01685597}

Submitted on 16 Jan 2018

HAL is a multi-disciplinary open access archive for the deposit and dissemination of scientific research documents, whether they are published or not. The documents may come from teaching and research institutions in France or abroad, or from public or private research centers.
L'archive ouverte pluridisciplinaire HAL, est destinée au dépôt et à la diffusion de documents scientifiques de niveau recherche, publiés ou non, émanant des établissements d'enseignement et de recherche français ou étrangers, des laboratoires publics ou privés. 


\title{
Ambient Humidity Influence on CO Detection with
}

\section{$\mathrm{SnO}_{2}$ Gas Sensing Materials - a Combined \\ DRIFTS/DFT Investigation}

\author{
Susanne Wicker ${ }^{\dagger,}$, Mathilde Guiltat ${ }^{2}$, Udo Weimar ${ }^{1}$, Anne Hémeryck ${ }^{2}$ and Nicolae Barsan ${ }^{{ }^{*}}$ \\ ${ }^{1}$ Tuebingen University, Faculty of Science, Department of Chemistry, Institute of Physical and \\ Theoretical Chemistry, Auf der Morgenstelle 15, 72076 Tuebingen, Germany \\ ${ }^{2}$ LAAS-CNRS, Université de Toulouse, CNRS, UPS, Toulouse, France
}

\begin{abstract}
Diffuse Reflectance Infrared Fourier Transform Spectroscopy (DRIFTS) and first-principles calculations are performed to investigate the different ways in which water reacts with a $\mathrm{SnO}_{2}$ surfaces and to evaluate the cross interference of humidity on the detection of CO. Two different materials, chosen because of their very different properties, were investigated. The experimental results were interpreted with the help of theoretical modelling of two clean and defective surfaces, namely (110) and (101). The experimental results show, and the theoretical calculations confirm, that water vapor can interfere with the $\mathrm{CO}$ detection in different ways depending on the active surface and the concentration of oxygen vacancies. This is related to the different ways in
\end{abstract}


which the water vapor reacts with tin oxide; on the one hand it can reduce the (101) surface, on the other hand it can heal the oxygen vacancies of the defective (110) surface.

\section{INTRODUCTION}

More than 60 years ago Heiland et al. ${ }^{1,2}$ showed that the conductivity of semiconducting metal oxides $(\mathrm{SMOX})$ (in that case, single crystalline $\mathrm{ZnO}$ ) depends on the composition of the surrounding atmosphere. More than 50 years ago Seiyama et al. ${ }^{3}$ proposed the coupling of SMOX with gas chromatographs ( $\mathrm{ZnO}$ thin film). The first gas sensors based on $\mathrm{SnO}_{2}$ were realized by Taguchi ${ }^{4}$, who later founded Figaro Eng., the first company to commercialize SMOX based gas sensors worldwide. Due to their inherent advantages - high sensitivity, low cost, potential for miniaturization, good stability - SMOX based sensors have been used in various applications e.g. explosive and toxic gas alarms, controls for air intake into car cabin, monitors for industrial processes etc.. . Most of the SMOX gas sensors are based on porous layers of $\mathrm{SnO}_{2}$ and $\mathrm{WO}_{3}$, because these oxides meet the application specific requirements of sensitivity and stability $^{6-8}$ and, currently, the drive is towards further miniaturization and increased selectivity and sensitivity in order to make possible their integration in a host of mobile and household devices and help make possible the Internet of Things (IoT). Gas sensing with semiconducting metal oxides (SMOX) based sensors in ambient conditions means that a changing humidity background needs to be taken into account. Considering how important this issue can be for practical applications, it is surprising that not too many publications focus on that. Generally, the publications dealing with humidity effect and $\mathrm{SnO}_{2}$, which is consider being the prototype SMOX for gas sensing, report a resistance decrease under humidity exposure at an operation temperature of $300^{\circ} \mathrm{C}^{9-11}$. This implies that $\mathrm{H}_{2} \mathrm{O}$ acts as a reducing gas, when reacting with $\mathrm{SnO}_{2}$ surface. 
The reducing effect is still best described with the reaction mechanisms proposed by Heiland and Kohl ${ }^{12}$ in 1988:

- The first mechanism includes the homolytic dissociation of $\mathrm{H}_{2} \mathrm{O}$ and its reaction with one lattice oxygen, $\mathrm{O}_{\mathrm{O}}$, to form one terminal hydroxyl group, $\left(\mathrm{Sn}_{\mathrm{Sn}}{ }^{+}-\mathrm{OH}^{-}\right)$, at a tin place, $\mathrm{Sn}_{\mathrm{Sn}}$, and one rooted hydroxyl group, $(\mathrm{OH})_{\mathrm{O}}^{+}$, which reacts as a surface donor freeing one electron, $\mathrm{e}^{-}$, to the conduction band. The reaction can be described by the following equation (1):

$$
\mathrm{H}_{2} \mathrm{O}+\mathrm{Sn}_{\mathrm{Sn}}+\mathrm{O}_{\mathrm{O}} \rightleftharpoons\left(\mathrm{Sn}_{\mathrm{Sn}}{ }^{+}-\mathrm{OH}^{-}\right)+(\mathrm{OH})_{\mathrm{O}}^{+}+\mathrm{e}^{-}
$$

- The second proposed mechanism includes also a reaction of water with lattice oxygen forming two terminal hydroxyl groups, $\left(\mathrm{Sn}_{\mathrm{Sn}}{ }^{+}-\mathrm{OH}^{-}\right)$, and one oxygen vacancy, $\mathrm{V}_{\mathrm{O}}{ }^{++}$. The formation of the latter is providing two electrons to the conduction band. The reaction is best described by the following equation (2):

$$
\mathrm{H}_{2} \mathrm{O}+2 \mathrm{Sn}_{\mathrm{Sn}}+\mathrm{O}_{\mathrm{O}} \rightleftharpoons 2\left(\mathrm{Sn}_{\mathrm{Sn}}{ }^{+} \mathrm{OH}^{-}\right)+\mathrm{V}_{\mathrm{O}}^{++}+2 \mathrm{e}^{-}
$$

So, the formation of hydroxyl groups is linked to the reducing effect of water on $\mathrm{SnO}_{2}$ and therefore the formation of hydroxyl groups under water vapor exposure should be directly correlated to a decrease in resistance of $\mathrm{SnO}_{2}$. However, as already published DRIFTS spectra and resistance data show ${ }^{13}$, the reality is more complicated: the effect of humidity on two inhouse prepared materials show that although significantly more hydroxyl groups are formed on one material, IPC2, than the other, IPC, an opposite electrical effect is observable (see Fig. 1). 

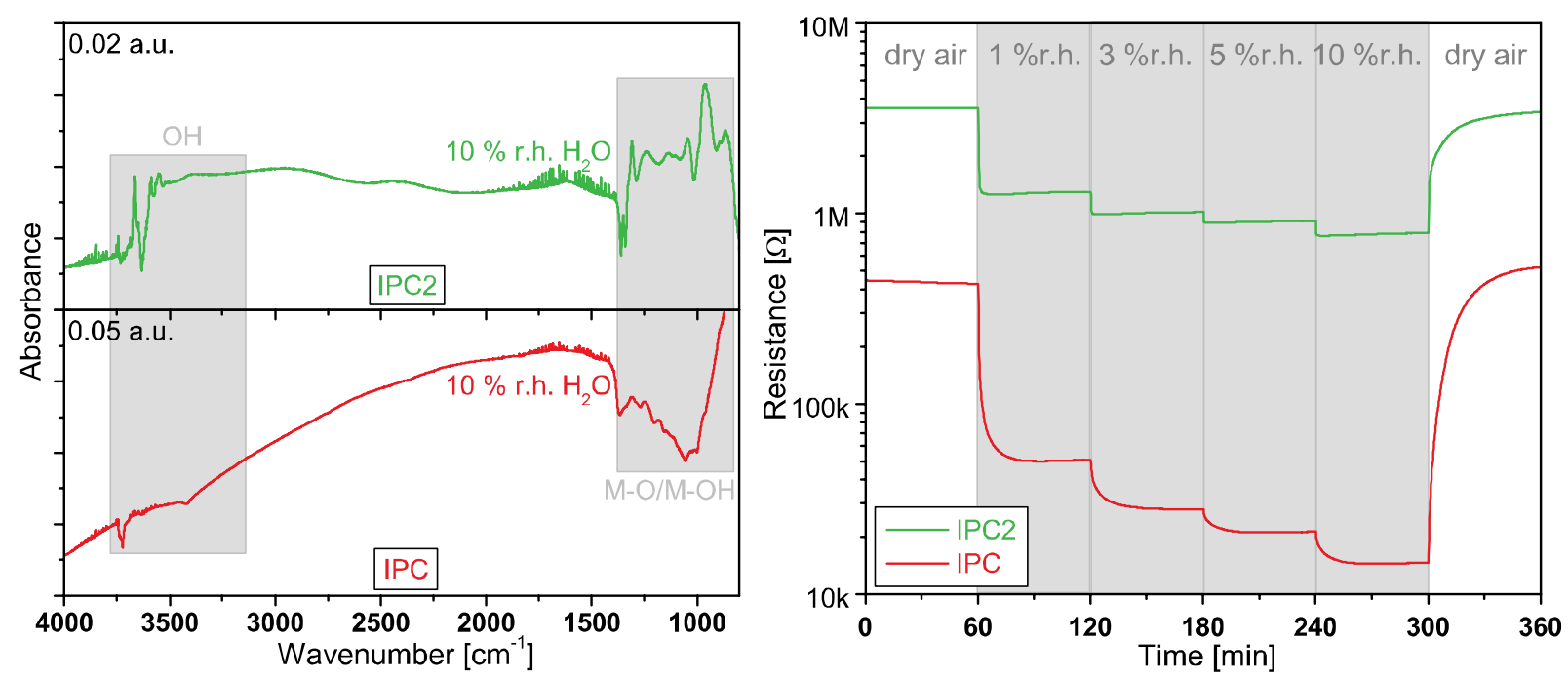

Figure 1. Left: DRIFTS absorbance spectra of IPC and IPC2 operated at $300{ }^{\circ} \mathrm{C}$ under exposure of $10 \%$ r.h. $\mathrm{H}_{2} \mathrm{O} @ 25{ }^{\circ} \mathrm{C}$; reference spectra: dry syn. air; right: corresponding resistance measurements with $1,3,5$, and $10 \%$ r.h. $\mathrm{H}_{2} \mathrm{O} @ 25^{\circ} \mathrm{C}$ in dry syn. air background. Adapted from Reference 13.

The preparation of the two materials presented in Figure 1 is described in detail elsewhere ${ }^{13}$. It is important to note that they were both synthesized by an aqueous sol-gel route starting from tin chloride; the only difference is the calcination temperature, which was $1000^{\circ} \mathrm{C}$ for IPC and $450^{\circ} \mathrm{C}$ for IPC2.

Here, with the aim to clarify this apparent contradiction, further investigations were performed on two selected $\mathrm{SnO}_{2}$ materials by assessing the sensor performance and using in operando DRIFT spectroscopy; the selection criterion was the very different humidity related gas sensing behavior. One of the materials is prepared in house (IPC); the other is based on a commercially available powder (SA). A theoretical study based on first principles calculations is associated to the experimental investigation to detail the adsorption of isolated $\mathrm{H}_{2} \mathrm{O}$ and $\mathrm{CO}$ molecules on $\mathrm{SnO}_{2}$ surfaces and the effect of the humidity on $\mathrm{CO}$ detection. Carbon monoxide was chosen as a 
model gas for the understanding of the well documented interfering effect of humidity on the detection of target gases ${ }^{13-17}$.

\section{EXPERIMENTAL METHODS}

\section{Material synthesis}

IPC: The in house prepared $\mathrm{SnO}_{2}$ powder is gained through an aqueous sol-gel process starting with a $\mathrm{SnCl}_{4}$ solution. An ammonia solution is added dropwise. During this process both solutions are kept at $0^{\circ} \mathrm{C}$ and stirred thoroughly to ensure homogeneous and small precipitates of $\mathrm{Sn}(\mathrm{OH})_{4}$. The gained gel is washed several times with distilled water until a $\mathrm{pH}$-value of 7 is achieved. It is then dried at $120{ }^{\circ} \mathrm{C}$ and finally calcined in a tube furnace (Heraeus ROK 6/30) for $8 \mathrm{~h}$ at $1000{ }^{\circ} \mathrm{C}$ (IPC). A more detailed description of the synthesis and characterization of the material can be found in references 18 and 19.

SA: $\mathrm{A} \mathrm{SnO}_{2}$ powder (Sigma-Aldrich, $<100 \mathrm{~nm}$ particle size $(\mathrm{BET})$ ) is suspended in deionized water and a stock solution of deionized water and $\mathrm{HCl}$ is added. The whole suspension is stirred for $48 \mathrm{~h}$, then dried in an oven at $80^{\circ} \mathrm{C}$ (Heraeus UT12) and afterwards calcined at $450^{\circ} \mathrm{C}$ for $1 \mathrm{~h}$ in a tube furnace (Heraeus ROK 6/30).

\section{Sensor fabrication}

The sensitive layer of the sensor is applied onto the substrate by screen printing a paste of 1,2propanediol (Sigma Aldrich, 99.5+\% A.C.S. reagent) and the corresponding $\mathrm{SnO}_{2}$ powder. The mixture is ground with mortar and pistil until a homogenous viscous paste is achieved. During the screen printing process the as-prepared paste is pressed through the screen printing mask with a rubber squeegee onto $\mathrm{Al}_{2} \mathrm{O}_{3}$ substrates. The sensors are left to settle at r.t. for $1 \mathrm{~h}$ and dried in an oven (Heraeus UT12) at $80^{\circ} \mathrm{C}$ overnight. In the last step the sensors are annealed by heating 
them for $10 \mathrm{~min}$ each at $400-500-400^{\circ} \mathrm{C}$ with two steps to cool down by moving it through a tube furnace (Heraeus ROK 6/30).

\section{DC resistance measurements}

The changes of the sensing layer resistance are measured with a Keithley 199 electrometer. A computer controlled gas mixing system equipped with data acquisition cards and mass flow controllers provides various concentrations of the test gas $\mathrm{CO}$ as well as different humidity backgrounds $\left(0 \%\right.$ r.h. to $50 \%$ r.h. $\left.\mathrm{H}_{2} \mathrm{O} @ 25^{\circ} \mathrm{C}\right)$. The sensors are measured at an operation temperature of $300{ }^{\circ} \mathrm{C}$. The sensor signal is defined as the ratio of two resistances:

$$
\mathrm{S}=\text { Rreference gas / R test gas }
$$

\section{DRIFT spectroscopy}

The DRIFTS measurements are performed with an evacuated FT-IR spectrometer (Bruker V80v), which is equipped with a Harrick cell ("Praying Mantis"). In this cell a special sensor DRIFTS chamber is mounted. The spectrometer consists of an interferometer, a $\mathrm{KBr}$ window (beam splitter) and an infrared light is recorded with a LN-MCT-Narrow $24 \mathrm{~h}$ photo detector (Liquid Nitrogen cooled - Mercury cadmium telluride). The spectra are recorded every $15 \min$ with a resolution of $4 \mathrm{~cm}^{-1}$ and 1024 sample scans. The apodization function Blackman-Harris-3Term is applied and the aperture was set to $3.5 \mathrm{~mm}$ to ensure that the DRIFTS measurement is performed only on the sensitive layer. The evaluated absorbance spectra are calculated by dividing two single channels through one another:

Absorbance $=-\log ($ sample spectrum/reference spectrum $)$

For a better understanding of the procedure, see Fig. S1. 
In parallel to the DRIFTS measurements, the resistance changes of the mounted sensor are recorded with a Keithley 617 electrometer. The sensor is heated to $300^{\circ} \mathrm{C}$ and a computer controlled gas mixing system, which is equipped with mass flow controllers and a data acquisition card, provides the DRIFTS setup with the relevant test gases $\left({ }^{12} \mathrm{CO},{ }^{13} \mathrm{CO}, \mathrm{H}_{2} \mathrm{O}, \mathrm{D}_{2} \mathrm{O}\right)$ and gas concentrations.

\section{Raman spectroscopy}

The Raman spectra of the two sensors were recorded using a Renishaw inVia Reflex Raman spectrometer with an excitation wavelength of $532 \mathrm{~nm}$.

\section{THEORETICAL METHODS}

\section{Details of calculations}

The periodic calculations were performed using the DFT method based on the GGA approximation employing the PBE exchange-correlation functional as implemented in the planewaves program VASP ${ }^{20-22}$. Single point computations, from relaxed configurations, were performed following the scheme proposed by Heyd, Scuseria, and Ernzerhof (HSE) which separates the exchange energy into short-range and long-range components ${ }^{23-27}$. The projectoraugmented wave (PAW) potentials were applied for the core electron representation ${ }^{28,29}$. A converged value of $E_{c u t}=400 \mathrm{eV}$ was used for the cut-off energy of the plane wave. The integration in reciprocal space was performed with a Monkhorst-Pack grid ${ }^{30}$.

Two simulations cells are used. The stoichiometric $\mathrm{SnO}_{2}(101)$ and (110) surfaces are modeled by periodic slabs depicted in Fig. $2^{31-34}$. For the (101) surface, the cell is composed by a total number of 96 atoms with 32 tin atoms and 64 oxygen atoms corresponding to a cell dimension of $11.42 \times 9.47 \times 25.00 \AA^{3}$ with a surface area of $108.19 \AA^{2}$. For the (110) surface, the cell was 
composed by a total number of 96 atoms with 32 tin atoms and 64 oxygen atoms corresponding to a cell dimension of $9.48 \times 9.48 \times 25 \AA^{3}$ with a surface area of $89.87 \AA^{2}$. For both slabs, a vacuum zone of $15 \AA$ in the $\mathrm{z}$ direction was used to create a surface effect. $24 \mathrm{Sn}$ and $\mathrm{O}$ atoms were frozen in their bulk positions at the bottom of the cell to simulate a bulk effect. All other atoms were free to relax. The periodic slab was repeated in the three directions. A k-point mesh of $(2 \times 2 \times 1)$ was used. These simulation cell parameters have been checked to avoid any interaction with other periodic cells.

Both (110) and (101) surfaces exhibit two types of oxygen atoms on the surface (Figure 2.a-d): there are two-fold coordinated $\mathrm{O}$ atoms called out-of-plane oxygen atoms and denoted as Oo in the following. All other oxygen atoms below the surface layer and deeper into the bulk are threefold coordinated.

Defective surfaces, shown as sub-stoichiometric system containing one oxygen vacancy, have been obtained by removing a two-fold coordinated Oo atom from the surface layer. The corresponding energies of oxygen vacancy formation are $2.30 \mathrm{eV}$ and 2.25 on defective (110) and (101) surfaces respectively. Other three-fold coordinated oxygen atoms in the topmost layer exhibit higher energies of oxygen vacancy formation $(3.45 \mathrm{eV}$ and $3.64 \mathrm{eV}$ on defective (110) and (101) surfaces respectively ${ }^{27,31,32}$ ), so that they were not considered in this work. The energy of oxygen vacancy formation $\Delta \mathrm{Eo}$ was calculated by using the equation $\Delta \mathrm{E} 0=\mathrm{Evac}+$ 1/2EO2-Esurface where EO2 is the energy of the isolated spin polarized $\mathrm{O} 2$ molecule, Evac is the energy of a (110) surface or (101) surface with one oxygen vacancy per supercell, and Esurface is the energy of the stoichiometric surface.

Adsorptions of one water molecule are thus performed considering the topology of such clean and defective (110) and (101) surfaces. The isolated $\mathrm{H}_{2} \mathrm{O}$ and $\mathrm{CO}$ molecules were relaxed in the 
same simulation cell as the $\mathrm{SnO}_{2}(101)$ and (110) slabs. Their adsorption sites were identified by screening the respective topology of the (101) and (110) surfaces. Charges were obtained by calculating the difference of the atomic charges on all the atoms of the oxide before and after adsorption using the Bader charges analysis ${ }^{35}$.
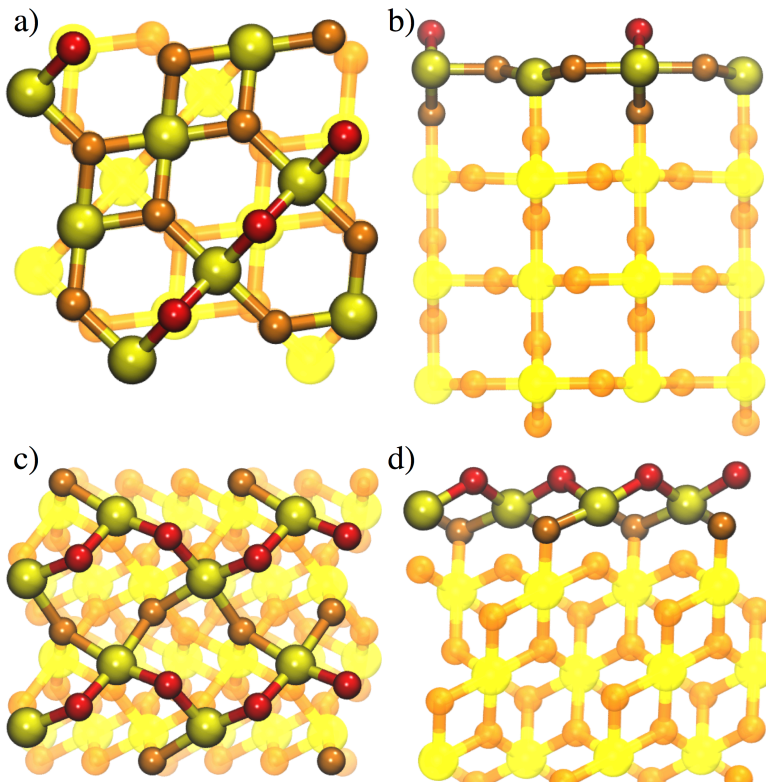

d)

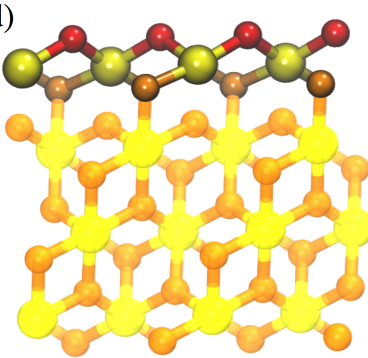

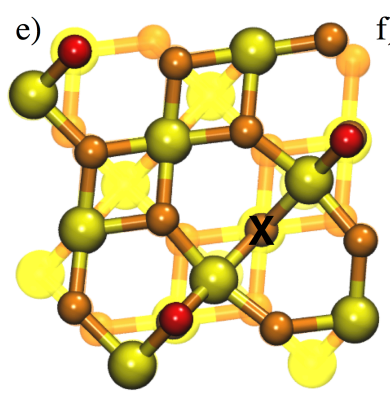
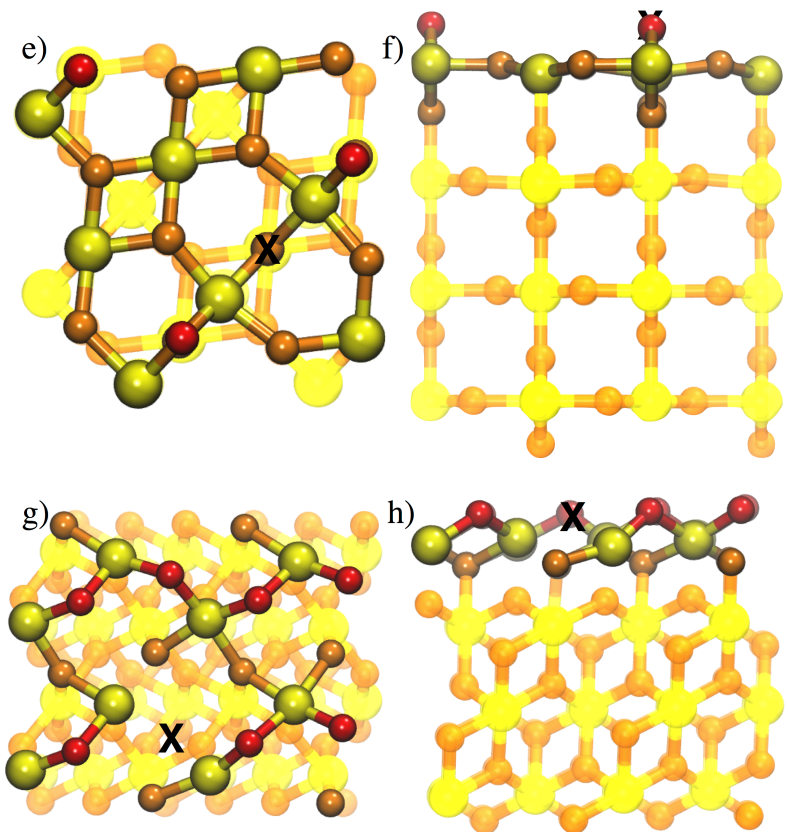

h)

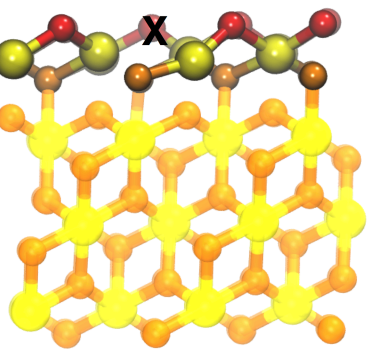

Figure 2. a) Top and b) side views of (110) surface. c) Top and d) side views of (101) surface. e) Top and f) side views of (110) surface containing an Oo vacancy. g) Top and h) side views of (101) surface containing an Oo vacancy. The black crosses on e) to h) indicate vacancy, where Oo atom has been removed from the topmost layer of the $\mathrm{SnO}_{2}$ substrates. Topmost layers of atoms are highlighted, whereas the layers below the surface are shadowed. Tin atoms are in yellow. Surface out-of-plane oxygen atoms are highlighted in red, other oxygen atoms are in orange. Color scheme and surface representation are used throughout the paper.

\section{Energetic considerations}

In this paper, the adsorption energies $\Delta \mathrm{E}_{\text {ads }}$ are calculated using the following formula: 
$\Delta \mathrm{E}_{\mathrm{ads}}=\mathrm{E}_{\text {adsorbed molecule }}-\mathrm{E}_{\text {surface }}-\mathrm{E}_{\text {gaseous molecule }}$

where $E_{\text {adsorbed molecule }}$ is the total energy of the system with a gaseous molecule adsorbed on the $\mathrm{SnO}_{2}$ surface, $\mathrm{E}_{\text {surface }}$ and $\mathrm{E}_{\text {gaseous molecule }}$ are the total energies of the relaxed surface and isolated gaseous molecule (either $\mathrm{H}_{2} \mathrm{O}$ or $\mathrm{CO}$ ), respectively. Conventionally, negative values indicate exothermic adsorption.

Activation barriers have been determined along the Minimum Energy Path using a drag method. Here, the system is relaxed; while one coordinate is held fixed along the diffusion pathway, all other coordinates of freedom in the system are relaxed. The maximum energy corresponds to the transition state and determines the activation barrier.

\section{EXPERIMENTAL RESULTS}

To investigate the impact of changing ambient humidity two different $\mathrm{SnO}_{2}$ materials were selected. One was prepared in house, IPC, via a sol-gel route and calcined at $1000^{\circ} \mathrm{C}$, while the other one, $\mathrm{SA}$, is based on a purchased $\mathrm{SnO}_{2}$ material, which underwent wet-chemical pretreatment and a calcination temperature of $450^{\circ} \mathrm{C}$. IPC shows a higher crystallinity, a larger average nanoparticles size $(110 \mathrm{~nm}$ vs. $30 \mathrm{~nm})$ and therefore a lower surface area than SA ${ }^{36-38}$. The measured BET surface areas, by $\mathrm{N}_{2}$ adsorption by using a Micrometrics ASAP 2020 instrument, are $23 \mathrm{~m}^{2} / \mathrm{g}$ for SA and $12.5 \mathrm{~m}^{2} / \mathrm{g}$ for IPC. The corresponding REM pictures and XRD spectra are shown in Fig. S2.

\section{Humidity dependence of baseline resistance}

The humidity influence on the baseline resistance of the two different $\mathrm{SnO}_{2}$ materials was studied by exposing the sensors to eight humidity levels; ranging from $0.4 \%$ to $80 \%$ r.h. @ $25^{\circ} \mathrm{C}$ (see Fig. 3). 


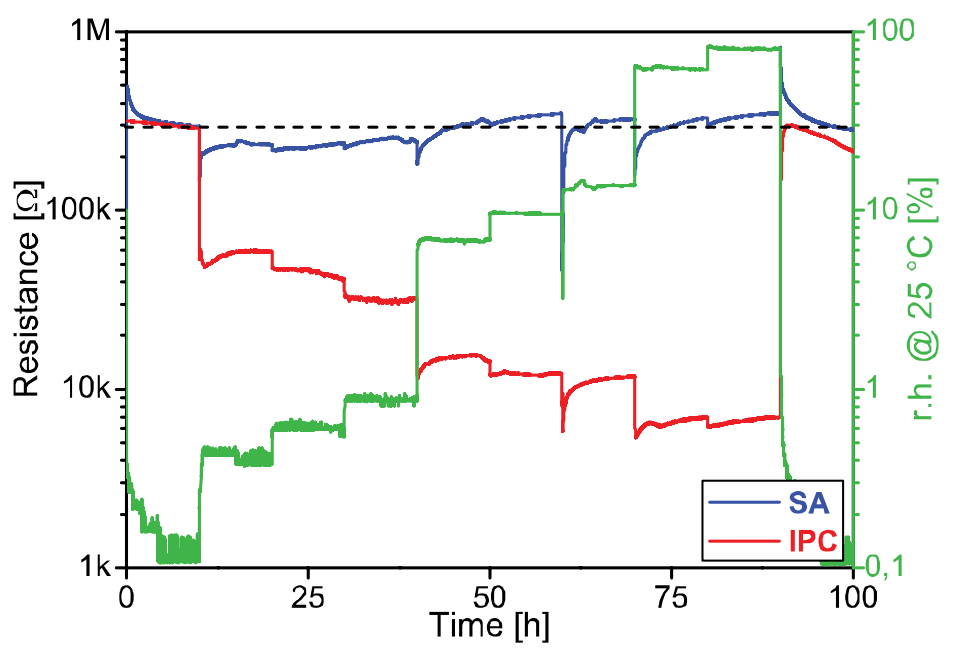

Figure 3. DC resistance measurements of IPC and SA in syn. air background at $300^{\circ} \mathrm{C}(0.1 \%$ r.h. @ $\left.25^{\circ} \mathrm{C}\right)$. The corresponding relative humidity $\left(0.4,0.6,0.9,7,10,14,62,80 \%\right.$ r.h.) @ $25^{\circ} \mathrm{C}$ is indicated on the right hand side y-axis.

It is quite obvious that the baseline resistance of IPC is strongly humidity dependent. Already the first increase from $0.1 \%$ r.h. (dry syn. air) to $0.4 \%$ r.h. @ $25^{\circ} \mathrm{C}$ determines a sensor signal of 5. Following increases of humidity, further decrease the baseline resistance; the corresponding sensor signals span from 5 to $44\left(89 \%\right.$ r.h. @ $\left.25^{\circ} \mathrm{C}\right)$.

On SA this is not the case; only slight changes with increasing water vapor background are observable. Moreover, while low relative humidity levels, up to $1 \%$ r.h. @ $25^{\circ} \mathrm{C}$, lead only to a minimal decrease in resistance, higher humidity levels even cause a slight increase in resistance. All in all the effects of water vapor on the baseline resistance of SA are almost negligible. The sensor signals range from 1.1 to 1.2.

The observations on IPC show a clear confirmation of the former reports that water vapor reacts as a reducing gas on $\mathrm{SnO}_{2}$. On the opposite, the findings on the $\mathrm{SA}$ do not fit into the 
current understanding. To get more information about the surface reaction mechanisms, operando DRIFT spectroscopy was used.

In Fig. 4, the DRIFT absorbance spectra of IPC and SA are displayed during exposure to $10 \%$ r.h. $\mathrm{H}_{2} \mathrm{O}$ as well as during exposure to its isotope, heavy water.

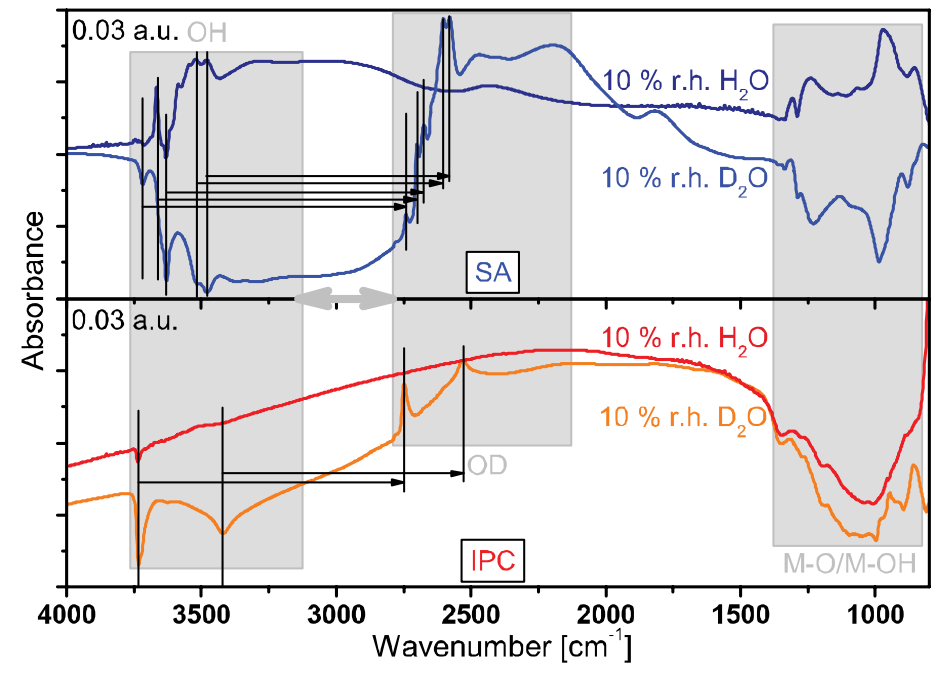

Figure 4. DRIFT absorbance spectra of SA and IPC under $10 \%$ r.h. $\mathrm{H}_{2} \mathrm{O}$ and $\mathrm{D}_{2} \mathrm{O} @ 25^{\circ} \mathrm{C}$ exposure in syn. air and at an operation temperature of $300^{\circ} \mathrm{C}$. Reference spectra: dry syn. air.

On IPC the formation of $\mathrm{OH}$ groups is hardly visible during water vapor exposure. However, a huge decrease in M-O vibration overtones is observable in the fingerprint region $1400-800 \mathrm{~cm}^{-1}$. As the exchange reaction of $\mathrm{OH}$ with $\mathrm{OD}$ groups during $\mathrm{D}_{2} \mathrm{O}$ exposure reveals, also only a few $\mathrm{OH}$ groups are preexisting in dry syn. air.

While during $\mathrm{H}_{2} \mathrm{O}$ exposure the IPC spectra are mainly defined by the reduction of the material, the spectra of SA are dominated by the formation of $\mathrm{OH}$ and $\mathrm{M}-\mathrm{OH}$ bending vibrations. Also, not only are there a lot of $\mathrm{OH}$ groups formed during $10 \%$ r.h. $\mathrm{H}_{2} \mathrm{O}$ exposure, but many are already present in dry syn. air, as the exchange with heavy water vapor reveals. 
All in all, the reaction mechanisms of water vapor on $\mathrm{SnO}_{2}$ proposed by Heiland and $\mathrm{Kohl}$ in 1988 are suitable to explain the observations made on IPC with its strong reduction under humidity and the formation of some hydroxyl groups ${ }^{12}$. Additionally, it can be assumed that the surrounding water vapor contributes to the reduction of the material by hindering its reoxidation, described by equation 3 .

$$
1 / 2 \mathrm{O}_{2}+\mathrm{V}_{\mathrm{O}}^{++}+2 \mathrm{e}^{-} \rightleftharpoons \mathrm{O}_{\mathrm{O}}
$$

The overall effect of humidity exposure is a decrease of the negative surface charge.

The findings obtained by testing the SA material cannot be similarly explained. The electrical measurements indicate that the surface charge remains unchanged suggesting that the reaction with water vapor is of an electroneutral nature. This implies that either, if there is a reduction, it is fully compensated by immediate reoxidation, or the formation of hydroxyl groups during water vapor exposure has no reducing effect on SA.

Which approach describes the occurring reaction mechanism the best can be verified by removing the possibility of reoxidation by dosing water in the absence of oxygen, id est. in nitrogen. The corresponding DRIFTS and resistance measurements are shown in Fig. S3. It was found that in the absence of oxygen even more hydroxyl groups are formed, while still hardly any electrical effect is observable. These results imply that water does not always react as a reducing gas on $\mathrm{SnO}_{2}$.

The findings can be best explained by an electrically neutral reaction in which an oxygen vacancy, $\mathrm{V}_{\mathrm{O}}^{++}$, is filled with a rooted hydroxyl group, $(\mathrm{OH})_{\mathrm{O}}^{+}$, and the residual hydrogen transforms an existing lattice oxygen, $\mathrm{O}_{\mathrm{O}}$, to a second rooted hydroxyl group, $(\mathrm{OH})_{\mathrm{O}}^{+}$.

$$
\mathrm{H}_{2} \mathrm{O}+\mathrm{V}_{\mathrm{O}}^{++}+\mathrm{O}_{\mathrm{O}} \rightleftharpoons 2(\mathrm{OH})_{\mathrm{O}}^{+}
$$


It means that the reaction with humidity on IPC is mainly dominated by the reduction of the material, whereas an electroneutral reaction mainly dominates on SA. In general, from the experimental results, it can be derived that the ability of a $\mathrm{SnO}_{2}$ surface to form hydroxyl groups seems to be inversely proportional to the electrical effect humidity has.

\section{Humidity cross-influence on CO sensing}

Humidity does not only have an effect on the baseline resistance of a SMOX material itself, but it also contributes to or interferes with the sensor response of other gases e.g. CO. It is well known that an increasing water vapor background has a negative impact on the gas sensor signal towards $\mathrm{CO}$ on undoped $\mathrm{SnO}_{2}{ }^{37,38}$. This is what is also observable on IPC and SA. In both cases the sensor signal decreases with increasing humidity background from 47/55 to 10/23 (IPC/SA) see Fig. S4.

To be able to understand the occurring reactions in more detail, DRIFT spectroscopy was also applied during $\mathrm{CO}$ exposure in both dry and humid conditions. The corresponding DRIFT spectra are displayed in Fig. 5.

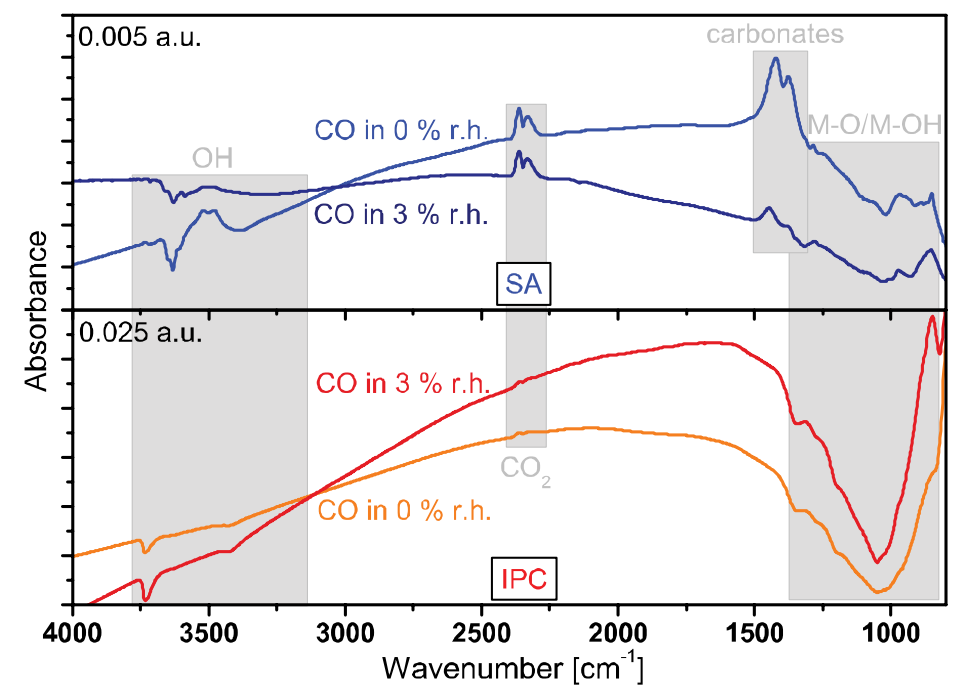


Figure 5. DRIFT absorbance spectra of 500 ppm of CO exposure in dry and in 3\% r.h. $\mathrm{H}_{2} \mathrm{O} @$ $25^{\circ} \mathrm{C}$ background on IPC and SA at an operation temperature of $300^{\circ} \mathrm{C}$. Reference spectra: dry syn. air and $3 \%$ r.h. $\mathrm{H}_{2} \mathrm{O} @ 25^{\circ} \mathrm{C}$, respectively.

In Fig. 5 it can be seen that on IPC both a reduction of the material as well as a decrease in the $\mathrm{OH}$ groups is visible during $\mathrm{CO}$ exposure in dry syn. air background. Both features are a bit more enhanced in a $3 \%$ r.h. $\mathrm{H}_{2} \mathrm{O} @ 25^{\circ} \mathrm{C}$ background. Due to the reducing nature of $\mathrm{CO}$ also some $\mathrm{CO}_{2}$ is formed, in both backgrounds. Its presence in the pores of the material causes the band at $2438 \mathrm{~cm}^{-1}$ with its rotational fine structure. The oxidation to $\mathrm{CO}_{2}$ can be expressed with the following reaction equation:

$$
\mathrm{CO}+\mathrm{O}_{\mathrm{O}} \rightleftharpoons \mathrm{CO}_{2, \mathrm{gas}}+\mathrm{V}_{\mathrm{O}}^{++}+2 \mathrm{e}^{-}
$$

Although also on SA gaseous $\mathrm{CO}_{2}$ is detectable, the other features differ. In addition to the $\mathrm{CO}_{2}$ band, some carbonate bands are visible, which are decreased in the humid background. For the $\mathrm{OH}$ bands a shift from terminal to rooted hydroxyl groups occurs in dry conditions, while in humid ones several $\mathrm{OH}$ groups are removed during $\mathrm{CO}$ exposure.

So, on both $\mathrm{SnO}_{2}$ materials it is obvious that during $\mathrm{CO}$ exposure only a weak removal of hydroxyl groups is visible, which implies that $\mathrm{CO}$ is hardly able to compete with humidity for reaction partners. This is very much in line with the observation of a decrease in sensor signals to $\mathrm{CO}$ in the background of water vapor.

However, if one has a look not to the relative changes (sensor signal), but to the absolute ones, it is obvious from the electrical results that the two $\mathrm{SnO}_{2}$ materials show opposite trends. For more details see Fig. 6. 

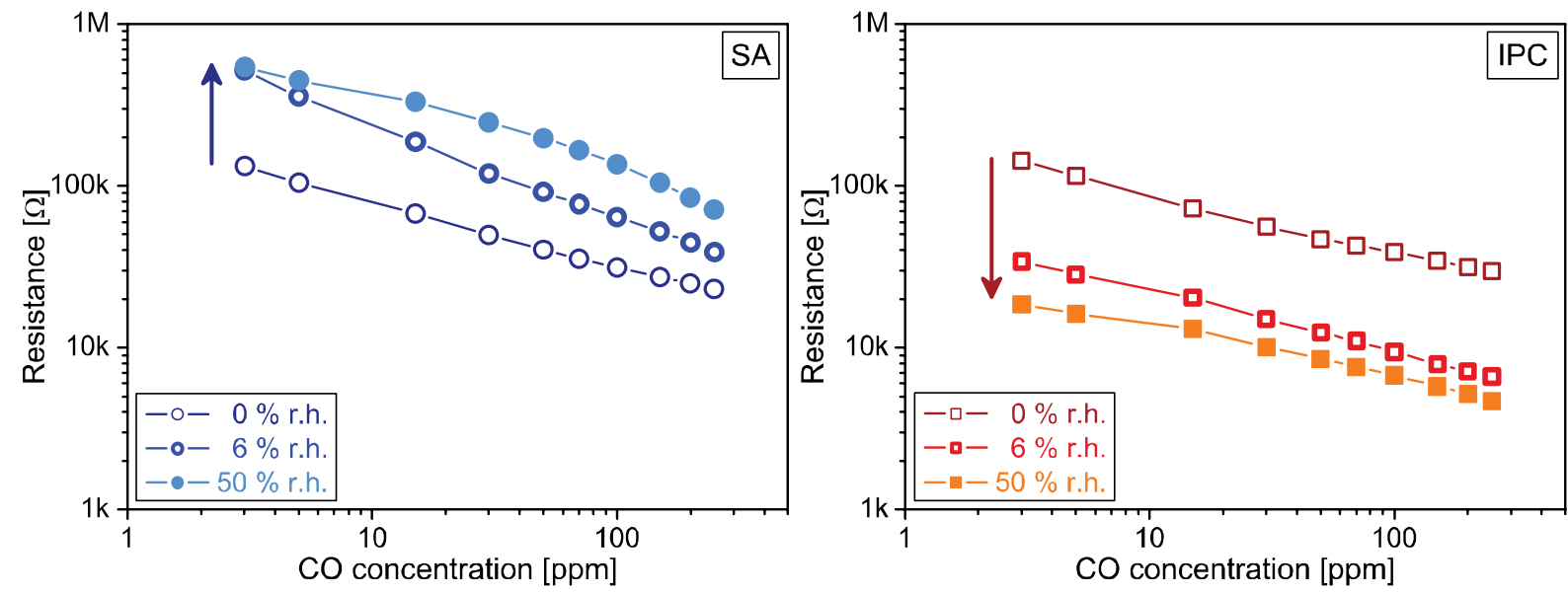

Figure 6. Sensor resistance values for SA (left) and IPC (right) under exposure of 3, 5, 15, 30, $50,70,100,150,200,250$ ppm CO in various humidity backgrounds $(0 \%, 6 \%$, and 50\% r.h. @ $25^{\circ} \mathrm{C}$ ) at an operation temperature of $300^{\circ} \mathrm{C}$. Results of IPC taken from ref. 17 . Arrows indicate the resistance increase (SA) and decrease (IPC) in increasing humidity backgrounds, respectively.

In the case of the IPC material one observes that the resistance drops not only by increasing the $\mathrm{CO}$ concentration, but also by increasing the humidity background. On the opposite, for SA the absolute resistance increases under $\mathrm{CO}$ exposure when the humidity increases.

Those observations can be explained by taking into consideration the different dominant water vapor reactions for those two materials:

On the one hand, on IPC, both $\mathrm{CO}$ and $\mathrm{H}_{2} \mathrm{O}$ contribute to the decrease of the resistance and, therefore, their effects are adding up. Both gases react with lattice oxygen, $\mathrm{O}_{\mathrm{O}}$, form oxygen vacancies, $\mathrm{V}_{\mathrm{O}}^{++}$, and free electrons to the conduction band. The fact that $\mathrm{CO}$ and water compete for the same reaction partner, namely lattice oxygen, is in line with the decrease of the sensor resistance and sensor signal to $\mathrm{CO}$ in the presence of humidity. 
On the other hand, on $\mathrm{SA}$, the reaction of $\mathrm{CO}$ is assumed to follow the same mechanism as on IPC forming $\mathrm{CO}_{2}$ by reacting with lattice oxygen. However, no direct competition for lattice oxygen takes place between $\mathrm{CO}$ and water vapor as the reaction with $\mathrm{CO}$ creates oxygen vacancies and water vapor fills them with rooted hydroxyl groups. It means that the presence of humidity seems to hinder the CO sensing in a different way e.g. some lattice oxygen are replaced by rooted hydroxyl groups and, therefore, not directly available for the reaction with CO. No additive effect on the sensor resistance is observable.

\section{THEORETICAL RESULTS AND DISCUSSION}

\section{$\mathrm{H}_{2} \mathrm{O}$ reactions with $\mathrm{SnO}_{2}$ surfaces}

DFT calculations have been conducted in order to assess the conclusions of the experiments. Two surface orientations are considered, id est. (110) and (101), with or without Oo vacancies, on which $\mathrm{H}_{2} \mathrm{O}$ and $\mathrm{CO}$ are adsorbed.

Both $\mathrm{H}_{2} \mathrm{O}$ and $\mathrm{CO}$ adsorptions have been widely studied using DFT calculations ${ }^{33,}{ }^{39-46}$. Concerning water adsorption, our findings (Fig. 7.a) indicate also a physisorbed mode on (110) surface with adsorption energy $-0.35 \mathrm{eV}$, and molecular adsorption modes are reported only on (101) surface (see Fig. 7.b). 
H2O molecular adsorption

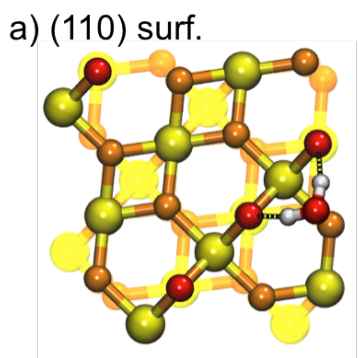

b) (101) surf.

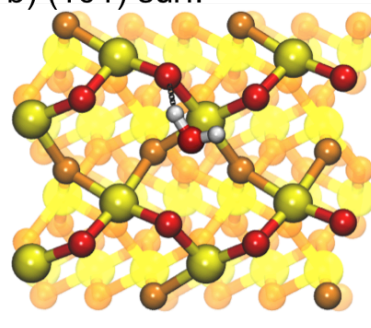

$\mathrm{H} 2 \mathrm{O}$ dissociative adsorption

c) (110) surf.

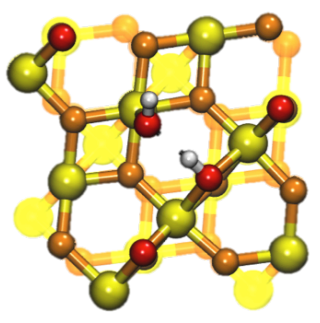

d) (101) surf.

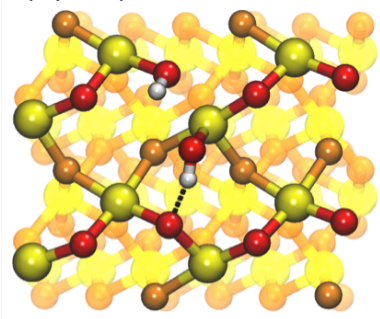

H2O molecular adsorption

e) Defective (110) surf. f) Defective (101) surf.

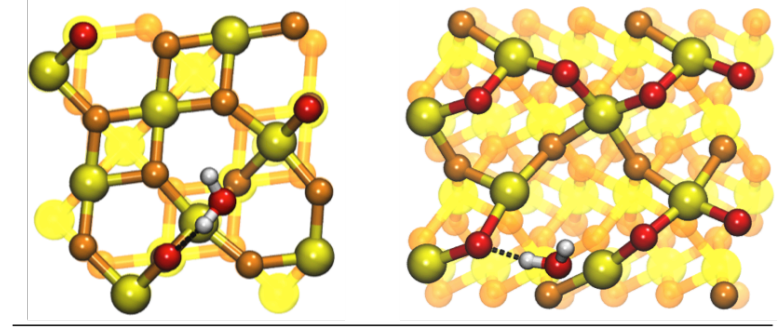

$\mathrm{H} 2 \mathrm{O}$ dissociative adsorption

g) Defective (110) surf.

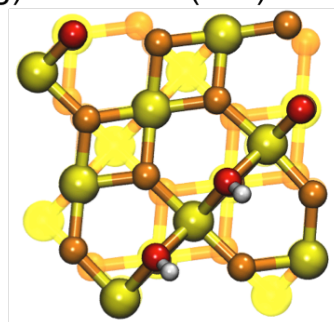

h) Defective (101) surf

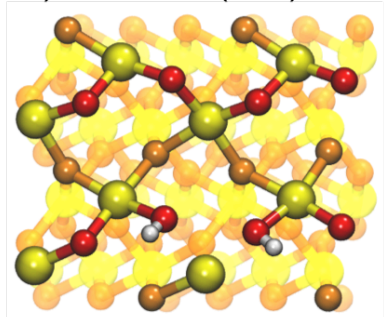

Figure 7. Adsorption modes of $\mathrm{H}_{2} \mathrm{O}$ : molecular mode on the clean a) (110) surface / b) (101) surface; dissociated mode on the clean c) (110) surface / d) (101) surface; molecular mode above a vacancy defect on the e) (110) surface / f) (101) surface; dissociated mode above a vacancy defect on the g) (110) surface / h) (101) surface. Hydrogen atoms are in white.

Dissociated states are the favored adsorption modes with adsorption energies larger than $-1 \mathrm{eV}$ for both surfaces. The dissociation of $\mathrm{H}_{2} \mathrm{O}$ molecule occurs through the adsorption of one $\mathrm{OH}$ group on one Sn atom and the adsorption of the dissociated $\mathrm{H}$ on one Oo atom ${ }^{33,40,42-45}$ (Fig. 7.c and 7.d).

\section{Clean surface}

On the (110) surface, the spontaneous dissociation of water molecule occurs preferentially on $\mathrm{Sn}$ and $\mathrm{O}$ atoms, which are first neighbors (Fig. 7.c) because of the formation of a $\mathrm{H}$-bond between the dissociated $\mathrm{H}$ atom coming from the water molecule and the dissociated $\mathrm{OH}$ adsorbed on $\mathrm{Sn}$ 
atom $(\mathrm{d}(\mathrm{H} \text { bond })=1.79 \AA)^{34,35,43,44}$. Here the two bonds between Sn-Oo are slightly enlarged, from $2.00 \AA$ to $2.16 \AA$ but not broken. The corresponding adsorption energy is $-1.87 \mathrm{eV}$ and the reaction of water adsorption on (110) can be written as:

$$
\mathrm{H}_{2} \mathrm{O}_{\mathrm{gas}}+\mathrm{Sn}_{\mathrm{Sn}}+\mathrm{Sn}_{\mathrm{Sn}}-\mathrm{O}_{\mathrm{O}}-\mathrm{Sn}_{\mathrm{Sn}} \rightleftharpoons \mathrm{Sn}_{\mathrm{Sn}}-\mathrm{OH}+\mathrm{Sn}_{\mathrm{Sn}}-\mathrm{O}_{\mathrm{O}} \mathrm{H}-\mathrm{Sn}_{\mathrm{Sn}}
$$

So, in this case we do not observe the formation of the oxygen vacancies because of the interaction with water vapor. This is supporting the first mechanism proposed by Heiland and Kohl ${ }^{12}$. However, the electrical effect seems to be very limited, $-0.12 \mathrm{e}$, when compared to the one correlated with the formation of oxygen vacancies, $-1 \mathrm{e}$.

On the (101) surface, the dissociation of water on first neighbors Oo and Sn atom results in two hydroxyl groups $(\mathrm{OH})$. On the opposite to what is observed on the (110) surface, one Sn-Oo bond from the surface breaks $(\mathrm{d}(\mathrm{Sn}-\mathrm{O})=2.30 \AA)$ when $\mathrm{H}$ adsorbs on Oo atom (Fig. 7.d indicated by the dashed line in Eq. 7). The calculated adsorption energy is $-1.50 \mathrm{eV}$ and the reaction can be written as:

$$
\mathrm{H}_{2} \mathrm{O}_{\mathrm{gas}}+\mathrm{Sn}_{\mathrm{Sn}}+\mathrm{Sn}_{\mathrm{Sn}}-\mathrm{O}_{\mathrm{O}}-\mathrm{Sn}_{\mathrm{Sn}} \rightleftharpoons \mathrm{Sn}_{\mathrm{Sn}}-\mathrm{OH}+\mathrm{Sn}_{\mathrm{Sn}}-\mathrm{O}_{\mathrm{O}} \mathrm{H}^{\cdots} \mathrm{Sn}_{\mathrm{Sn}}
$$

In this case we see the first step in the formation of an oxygen vacancy. We still have the oxygen atom close to the position it would have in the surface lattice and that is the reason we were writing it as $\mathrm{Sn}_{\mathrm{Sn}}-\mathrm{O}_{\mathrm{O}} \mathrm{H}^{\cdots} \mathrm{Sn}_{\mathrm{Sn}}$. The electrical effect is still limited, -0.16e, when compared to the formation of an oxygen vacancy but larger than in the case of the real rooted hydroxyl groups formed on the (110) surface.

\section{Defective surface}


In the case of defective (101) and (110) surfaces, the molecular adsorption is enhanced above a vacancy thanks to shorter $\mathrm{H}$-bonds that can be formed between the water molecule and the $\mathrm{O}_{\mathrm{O}}$ atoms placed in close vicinity ${ }^{34,43}$. Noteworthy, we observed a molecular adsorption (Fig. 7.e and f), with calculated adsorption energies of $-0.75 \mathrm{eV}$ and $-1.00 \mathrm{eV}$ on (110)- $\mathrm{V}$ and (101)- $\mathrm{V}$ surfaces, respectively). The dissociative adsorption of water molecule is still the favored process. It occurs similarly to the atomistic reaction observed on clean surfaces, where $\mathrm{OH}$ and $\mathrm{H}$ react with $\mathrm{Sn}$ and $\mathrm{O}_{\mathrm{O}}$ atoms, respectively.

In the case of the (110) surface, the most favorable case is obtained when $\mathrm{OH}$ dissociates on the under-coordinated $\mathrm{Sn}$ atom, healing the vacancy by reforming the $\mathrm{Sn}-\mathrm{O}$ bonds, and the $\mathrm{H}$ atom is adsorbed on a distant $\mathrm{O}_{\mathrm{O}}$ atom of the surface (Fig. 7.g). The adsorption energy is larger by 0.39 $\mathrm{eV}$ compared to the clean surface $(-2.26 \mathrm{eV} v s .-1.87 \mathrm{eV})$. The healing of the vacancy by the adsorption of $\mathrm{OH}$ into $\mathrm{V}_{\mathrm{O}}$ is the most favorable scenario for water adsorption on the (110) defective surface and can be summarized as:

$$
\mathrm{H}_{2} \mathrm{O}_{\mathrm{gas}}+\mathrm{Sn}_{\mathrm{Sn}}-\mathrm{O}_{\mathrm{O}}-\mathrm{Sn}_{\mathrm{Sn}}+\mathrm{Sn}_{\mathrm{Sn}} \cdots \mathrm{V}_{\mathrm{O}} \cdots \mathrm{Sn}_{\mathrm{Sn}} \rightleftharpoons \mathrm{Sn}_{\mathrm{Sn}}-\mathrm{O}_{\mathrm{O}} \mathrm{H}-\mathrm{Sn}_{\mathrm{Sn}}+\mathrm{Sn}_{\mathrm{Sn}}-\mathrm{OH}-\mathrm{Sn}_{\mathrm{Sn}}
$$

The electrical effect of the vacancy healing process on (110) is negligible, $-0.07 \mathrm{e}$, which supports the assumption of electroneutrality we made.

In the case of the (101) surface, the most favorable case is obtained when the $\mathrm{OH}$ group, resulting from the dissociation of water on the under-coordinated Sn atom, fills the vacancy, and the $\mathrm{H}$ atom adsorbs on one of the Oo atom neighboring the vacancy (Fig. 7.h). For the former process, the adsorption energy is larger by $0.64 \mathrm{eV}$, when compared to the clean surface ($2.14 \mathrm{eV} v s-1.50 \mathrm{eV})$. The $\mathrm{Sn}-\mathrm{O}$ bond is still broken. For the latter process, when the $\mathrm{H}$ atom 
adsorbs on the Oo atom, a Sn-Oo bond also breaks, similarly to the case of the clean surface. The corresponding reaction can be written as:

$$
\mathrm{H}_{2} \mathrm{O}_{\mathrm{gas}}+\mathrm{Sn}_{\mathrm{Sn}}-\mathrm{O}_{\mathrm{O}}-\mathrm{Sn}_{\mathrm{Sn}}+\mathrm{Sn}_{\mathrm{Sn}}{ }^{\cdots} \mathrm{V}_{\mathrm{O}} \cdots \mathrm{Sn}_{\mathrm{Sn}} \rightleftharpoons \mathrm{Sn}_{\mathrm{Sn}}-\mathrm{O}_{\mathrm{O}} \mathrm{H}^{\cdots} \mathrm{Sn}_{\mathrm{Sn}}+\mathrm{Sn}_{\mathrm{Sn}}-\mathrm{OH}^{\cdots} \mathrm{Sn}_{\mathrm{Sn}}
$$

The electrical effect is a bit larger than in the case of the (110) surface, because of the incipient oxygen vacancy formation, namely $-0.12 \mathrm{e}$, but still very small, when compared to the full formation of the oxygen vacancy.

Our calculations for water vapor adsorption on $\mathrm{SnO}_{2}$ show that it starts with the dissociation of the water molecule. The resulting hydroxyl group will react differently on clean and defective surfaces. In the first case, it will form a bond to the surface tin atom, id est. a terminal hydroxyl group. In the second case, it will preferably react with the surface oxygen vacancy forming rooted hydroxyl groups. There is a difference between the two surfaces, namely in the case of (110) the filling of the vacancy is made by forming bonds between the oxygen from the hydroxyl group and the two neighboring tin atoms. In the case of (101), only one bond is formed, between the oxygen and a neighboring tin atom, the second one is broken.

The resulting hydrogen atom always reacts with out-of-plane lattice oxygen atoms for both clean and defective surfaces. There is also a difference between the two surfaces: a bond between a tin atom and the out-of-plane oxygen atom breaks, when a hydrogen atom adsorbs on the outof-plane oxygen atom on the (101), but there is no bond breaking in the case of (110).

The findings from the DFT calculations suggest that the differences between the experimental results obtained for the two different materials could be determined by their different dominant surface orientation and concentration of oxygen vacancies. In the case of the IPC material the theoretical results indicate a very "clean" (101) surface. On the opposite, for the SA material one 
expects to have a defective (110) surface. It is very difficult to have an experimental proof for the presence of a dominant surface so, at this stage, we do not know that for sure. For the case of oxygen vacancies, we have some indications from the results of a Raman investigation performed on sensors at RT and presented in Figure 8.


Figure 8. Raman spectra of IPC (left) and SA (right).

The broad band of SA, which is observed between 370 and $820 \mathrm{~cm}^{-1}$, consists of a series of bands, namely the $A_{1 g}\left(633 \mathrm{~cm}^{-1}\right), B_{2 g}\left(774 \mathrm{~cm}^{-1}\right)$ and $E_{g}\left(475 \mathrm{~cm}^{-1}\right)$ lattice modes and three additional bands. A Diéguez et al. assigned these additional bands to the IR-active $\mathrm{A}_{2 \mathrm{u}}$ mode $\left(\sim 692 \mathrm{~cm}^{-1}\right)$ and two broad bands S1 and S2, which they found between $568-576 \mathrm{~cm}^{-1}$ and 493 $542 \mathrm{~cm}^{-1}$, respectively and that were assigned to the defective surface region of the $\mathrm{SnO}_{2}$ grains ${ }^{47}$. L. Lui et al. found, that the $S 1\left(\sim 573 \mathrm{~cm}^{-1}\right)$ band arises from oxygen vacancies ${ }^{48}$. For IPC a similar broad band is not observed. Consequently we do believe that the presence of the S1 and S2 bands indicates the presence of oxygen vacancies for the SA material.

$\mathrm{CO}$ reactions with $\mathrm{SnO}_{2}$ surfaces 
As already mentioned, $\mathrm{CO}$ reacts with Oo atom of the surface resulting in the formation of a $\mathrm{CO}_{2}$ molecule and a vacancy on the $\mathrm{SnO}_{2}$ surfaces, as described in ref. 26 on the $\mathrm{SnO}_{2}(101)$ surfaces. We found the same surface reduction also for the (110) surface with a calculated energy gain of $-1.55 \mathrm{eV}$.

Adsorption/reaction of $C O$ in the presence of humidity

We studied the effect of humidity on $\mathrm{CO}$ detection by considering pre-adsorbed $\mathrm{OH}$ groups on the $\mathrm{SnO}_{2}$ surfaces. The goal, here, is to find out if the reduction of the surface still occurs even in the presence of hydroxyl groups. We performed the calculations on the most stable dissociated states of water molecules on both clean and defective (110) and (101) surfaces (see Fig. 7.c and 7.d.). We observed that the spontaneous adsorption of CO found on clean (101) and (110) surfaces are inhibited on the hydroxylated areas of (101) and (110) surfaces: a CO molecule initially placed $2 \AA$ far from the surface as conducted conventionally in adsorption process using DFT study is repelled upwards further from the surface to an equilibrium adsorption state where no more interaction exists. In conclusion, adsorbed hydroxyls act as a repelling species for $\mathrm{CO}$ adsorption on $\mathrm{SnO}_{2}$ surfaces.

To force the reaction of $\mathrm{CO}$ with the hydroxylated surface, a drag method was applied on the $\mathrm{z}$ direction perpendicular to the surface and above the $\mathrm{OH}$ groups. We mainly observe the deviation of the $\mathrm{CO}$ molecule from hydroxylated parts of the surface to reach clean parts allowing the adsorption of $\mathrm{CO}$ on clean parts as described above. From a spontaneous adsorption on both tin oxide surfaces, the adsorption of $\mathrm{CO}$ becomes thermally activated in the presence of humidity. Activation barriers have been estimated larger than $0.40 \mathrm{eV}$. 
Combining the insights obtained from the theoretical calculations for both humidity and $\mathrm{CO}$ one can state the following:

- In the case of the IPC material, considered to be described by the clean (101) surface, we are expecting an additive electrical effect of (1) the incipient formation of oxygen vacancies, because of the reaction with water vapor, and (2) the formation of oxygen vacancies, which takes place on the non-hydroxylated parts, because of the reduction with $\mathrm{CO}$. In the presence of humidity the effect of $\mathrm{CO}$ will be reduced, because there will be less "free" $\mathrm{SnO}_{2}$ surface to react with. The resistance will be lower in the presence of both gases, because both of them are having an electrical effect.

- In the case of the SA material, considered to be described by the defective (110) surface, we are expecting that the reaction with water vapor will not change the electrical resistance because the process of healing oxygen vacancies by filling them with hydroxyl groups is neutral. The exposure to $\mathrm{CO}$ will result in a lower concentration of oxygen vacancies in the presence of humidity due to the decrease of the reactive "free" $\mathrm{SnO}_{2}$ surface. The total resistance in the presence of both humidity and $\mathrm{CO}$ will be lower that in the presence of $\mathrm{CO}$ only.

\section{CONCLUSIONS}

Based on this work the current understanding of water vapor impact on $\mathrm{SnO}_{2}$, namely humidity behaving as a reducing gas, has to be changed to include the concept that humidity can also act in an electroneutral way. A new reaction mechanism was proposed, in which two rooted hydroxyl groups can be formed by $\mathrm{H}_{2} \mathrm{O}$ adsorption on lattice oxygen and an oxygen vacancy. Furthermore, it was shown that the way in which humidity reacts on the respective $\mathrm{SnO}_{2}$ surface, 
also affects its cross-interference in the detection of CO. Because the two materials chosen for our study are describing the extreme cases we found in our extended $\mathrm{SnO}_{2}$ investigation, it is to be expected that in most cases both types of surface reactions coexist and it is even possible that depending on the ambient conditions their respective weights change. Our findings are also opening up intriguing synthesis strategy avenues, because the theoretical studies suggest, that this different type of electrical effects are associated to different surfaces and different concentrations of oxygen vacancies. Furthermore, our results suggest that the role of oxygen vacancies is not fully understood and complete the recent findings for $\mathrm{WO}_{3}$, where we even observed the oxidation of the material in the presence of humidity ${ }^{49}$.

Our attempt to explain the effect of humidity is also an example of what can be achieved by combining advanced operando investigations with theoretical calculations. The experiments are pointing the theory to the relevant tasks, in our case the finding of surface reactions that are electroneutral, while the theory highlights the weaknesses of the modeling based only on experiments, in our case the absence of a full reduction of the surface by water vapor even in the case of the (101) clean surface. However, even if the combination of those both approaches is a very powerful investigation tool it does not provide a definitive proof for the correctness of the proposed models. For that to happen there is still need for additional experimental work, which could be provided by studies on single crystalline or epitaxial layers. These type of model systems will need to be thoroughly studied, in operando conditions.

\section{AUTHOR INFORMATION}

\section{Corresponding Author}


* Nicolae Barsan, Tuebingen University, Faculty of Science, Department of Chemistry, Institute of Physical and Theoretical Chemistry, Auf der Morgenstelle 15, 72076 Tuebingen, Germany; nb@ipc.uni-tuebingen.de

\section{Present Addresses}

$\dagger$ Bosch Sensortec GmbH, Gerhard-Kindler-Straße 9, 72770 Reutlingen/Kusterdingen, Germany

\section{Author Contributions}

The manuscript was written through contributions of all authors. All authors have given approval to the final version of the manuscript.

\section{ACKNOWLEDGMENT}

The theoretical part of this work was conducted in the frame of the France Campus - PHC PROCOPE 2107 - Project $N^{\circ} 37744 T G$. The computer simulations were performed using HPC resources from CALMIP (Grant 16038).

The Raman measurements were performed with the help of Dr. Christoph Berthold from the Department of Geosciences of the University of Tuebingen and of Dr. David Degler from the Department of Chemistry of the University of Tuebingen. The BET measurements were performed by Leilei Luo and Dr. Yucang Liang from the Department of Chemistry of the University of Tuebingen.

\section{REFERENCES}


(1) G. Heiland, Zum Einfluß von adsorbiertem Sauerstoff auf die elektrische Leitfähigkeit von Zinkoxydkristallen, Zeitschrift Für Phys. 138 (1954) 459-464. doi:10.1007/BF01340692.

(2) G. Heiland, Zum Einfluß von Wasserstoff auf die elektrische Leitfähigkeit an der Oberfläche von Zinkoxydkristallen, Zeitschrift Für Phys. 148 (1957) 15-27.

(3) T. Seiyama, A. Kato, K. Fujiishi, M. Nagatani, A New Detector for Gaseous Components Using Semiconductive Thin Films, Anal. Chem. 34 (1962) 5-6.

(4) Taguchi, N., Japanese Patent S45-38200 (application in 1962).

(5) J. Watson, K. Ihokura, G.S. V Coles, The tin dioxide gas sensor, Meas. Sci. Technol. 4 (1993) 711-719. doi:10.1088/0957-0233/4/7/001.

(6) K. Ihokura, J. Watson, The Stannic Oxide Gas SensorPrinciples and Applications, CRC Press 1994, Boca Raton, Florida, USA, 1994.

(7) D.E. Williams, Semiconducting oxides as gas-sensitive resistors, Sensors Actuators B Chem. 57 (1999) 1-16. doi:10.1016/S0925-4005(99)00133-1.

(8) N. Barsan, D. Koziej, U. Weimar, Metal oxide-based gas sensor research: How to?, Sensors Actuators B Chem. 121 (2007) 18-35. doi:10.1016/j.snb.2006.09.047.

(9) Rank, S. The Influence of the Electrode Material on the Sensor Characteristics of $\mathrm{SnO}_{2}$ Thick Film Gas Sensors PhD thesis, Eberhard Karls Universität Tübingen, 2014. 
(10) Choi, K.-I.; Hübner, M.; Haensch, A.; Kim, H.-J.; Weimar, U.; Lee, J.-H. Ambivalent Effect of Ni Loading on Gas Sensing Performance in $\mathrm{SnO}_{2}$ Based Gas Sensor. Sensors Actuators B 2013 183, 401-410.

(11) Barsan, N.; Weimar, U. Understanding the Fundamental Principles of Metal Oxide based Gas Sensors; the Example of CO Sensing with $\mathrm{SnO} 2$ Sensors in the Presence of Humidity. $J$. Phys. Condens. Matter 2003, 15, R813-R839.

(12) Heiland, G.; Kohl, D. Chemical Sensor Technology, Vol.1 ed. Elsevier B.V., 1988, 1538.

(13) Degler, D.; Wicker, S.; Weimar, U.; Barsan, N. Identifying the Active Oxygen Species in $\mathrm{SnO}_{2}$ Based Gas Sensing Materials: An Operando IR Spectroscopy Study. J. Phys. Chem. C 2015, 119, 11792-11799.

(14) Barsan, N.; Hübner, M.; Weimar, U. Conduction Mechanisms in $\mathrm{SnO}_{2}$ based Polycrystalline Thick Film Gas Sensors Exposed to $\mathrm{CO}$ and $\mathrm{H}_{2}$ in Different Oxygen Backgrounds. Sensors Actuators B 2011, 157, 510-517.

(15) Hübner, M.; Pavelko, R. G.; Barsan, N.; Weimar, U. Influence of Oxygen Backgrounds on Hydrogen Sensing with $\mathrm{SnO}_{2}$ Nanomaterials. Sensors Actuators B 2011, 154, 264-269.

(16) Grossmann, K.; Pavelko, R. G.; Barsan, N.; Weimar, U. Interplay of $\mathrm{H}_{2}$, Water Vapor and Oxygen at the Surface of $\mathrm{SnO}_{2}$ based Gas Sensors - An Operando Investigation Utilizing Deuterated Gases. Sensors Actuators B 2012, 166-167, 787-793. 
(17) Rebholz, J. Influence of Conduction Mechanism Changes and Related Effects on the Sensing Performance of Metal Oxide Based Gas Sensors, PhD thesis, Eberhard Karls Universität Tübingen, 2016.

(18) Diéguez, A.; Romano-Rodríguez, A.; Morante, J. R.; Kappler, J.; Bârsan, N.; Göpel, W. Nanoparticle Engineering for Gas Sensor Optimisation: Improved Sol-Gel Fabricated Nanocrystalline $\mathrm{SnO}_{2}$ Thick Film Gas Sensor for $\mathrm{NO}_{2}$ Detection by Calcination, Catalytic Metal Introduction and Grinding Treatments. Sensors Actuators B 1999, 60, 125-137.

(19) Diéguez, A.; Vilà, A.; Cabot, A.; Romano-Rodriguez, A.; Morante, J. R.; Kappler, J.; Bârsan, N.; Weimar, U.; Göpel, W. Influence on the Gas Sensor Performances of the Metal Chemical States Introduced by Impregnation of Calcinated $\mathrm{SnO}_{2}$ Sol-Gel Nanocrystals. Sensors Actuators B, 2000, 68, 94-99.

(20) Kresse, G.; Hafner, J. Ab initio molecular-dynamics simulation of the liquid-metalamorphous-semiconductor transition in germanium. Phys. Rev. B 1994, 49, 14251.

(21) Kresse, G.; Furthmuller, J. Efficiency Of Ab-Initio Total Energy Calculations for Metals and Semiconductors using a Plane-Wave Basis Set. Comput. Mater. Sci. 1996, 6, 15.

(22) Perdew, J.P.; Burke, K.; Ernzerhof M. Generalized Gradient Approximation made simple. Phys. Rev. Lett. 1996, 77, 3865.

(23) Pacchioni, G. First Principles Calculations on Oxide-Based Heterogeneous Catalysts and Photocatalysts: Problems and Advances, Catalysis Letters 2015, 145, 80-94. 
(24) Gerosa, M.; Bottani, C.E. ; Caramella, L. ; Onida, G. ; Di Valentin, C. ; Pacchioni, G. Defect calculations in semiconductors through a dielectric-dependent hybrid DFT functional: The case of oxygen vacancies in metal oxides, J. Chem. Phys. 2015, 143, 134702.

(25) Dou, M.; Persson, C. Comparative study of rutile and anatase $\mathrm{SnO}_{2}$ and $\mathrm{TiO}_{2}$ : Band-edge structures, dielectric functions, and polaron effects, J. Appl. Phys. 2015, 113, 083703.

(26) Agoston, P.; Albe, K. ; Nieminen, R. M.; Puska, M. J. Intrinsic n-Type Behavior in Transparent Conducting Oxides: A Comparative Hybrid-Functional Study of In2O3, SnO2, and ZnO, Phys. Rev. Lett. 2009, 103, 245501.

(27) Trani, F. ; Causà, M. ; Ninno, D. ; Cantele, G. ; Barone, V. Density functional study of oxygen vacancies at the $\mathrm{SnO} 2$ surface and subsurface sites, Phys. Rev. B 2008, 77, 245410.

(28) Kresse, G.; Joubert, D. From Ultrasoft Pseudopotentials to the Projector AugmentedWave Method. Phys. Rev. B 1999, 59, 1758.

(29) Blochl, P.E. Projector Augmented-Wave Method. Phys. Rev. B 1994, 50, 17953.

(30) Monkhorst, H. J.; Pack, J. D. Special Points for Brillouin-Zone Integrations. Phys. Rev. B 1976, 13, 5188,

(31) Bergermayer W.; Tanaka, I. Reduced $\mathrm{SnO} 2$ surfaces by first-principles calculations Appl. Phys. Lett. 2004, 84, 909

(32) Manassidis, I.; Goniakowski, J.; Kantorovich, L. N.; Gillan, M. J. The Structure of the Stoichiometric and Reduced SnO2(110) Surface. Surf. Sci. 1995, 339, 258. 
(33) Batzill, M.; Bergermayer, W.; Tanaka, I.; Dieblod, U. Tuning the Chemical Functionality of a Gas Sensitive Material: Water Adsorption on SnO2(101). Surf. Sci. 2006, 600, L29-L32.

(34) Batzill, M.; Katsiev, K.; Burst, J. M.; Diebold, U.; Chaka, A. M.; Delley, B. Gas-phasedependent properties of $\mathrm{SnO}_{2}$ (110), (100), and (101) single-crystal surfaces: Structure, composition, and electronic properties. Phys. Rev. B 2005, 72, 165414.

(35) Tang, W.; Sanville, E.; Henkelman, G. A Grid-Based Bader Analysis Algorithm without Lattice Bias. J. Phys.: Condens. Matter 2009, 21, 084204.

(36) Kappler, J., Characterisation of high-performance $\mathrm{SnO}_{2}$ gas sensors for CO detection by in situ techniques, $\mathrm{PhD}$ thesis, Eberhard Karls University of Tuebingen, 2001.

(37) Großmann, K.; Wicker, S.; Weimar, U.; Barsan, N. Impact of Pt Additives on the Surface Reactions Between $\mathrm{SnO} 2$, Water Vapour, $\mathrm{CO}$ and $\mathrm{H}_{2}$ : An Operando Investigation. Phys. Chem. Chem. Phys. 2013, 15, 19151-8.

(38) Wicker S., Influence of humidity on the gas sensing characteristics of SnO2 - DRIFTS investigation of different base materials and dopants, $\mathrm{PhD}$ thesis, Eberhard Karls Universität Tübingen, 2016.

(39) Ducéré, J.M.; Hémeryck, A.; Estève, A.; Djafari Rouhani, M.; Landa, G.; Ménini, P.; Tropis, C.; Maisonnat, A.; Fau, P.; Chaudret, B. A Computational Chemist Approach to Gas Sensors: Modeling the Response of $\mathrm{SnO}_{2}$ to $\mathrm{CO}, \mathrm{O}_{2}$, and $\mathrm{H}_{2} \mathrm{O}$ Gases. J. Comput. Chem. 2012, 33, $247-258$.

(40) Bates, S.P. Full-Coverage Adsorption of Water on SnO2(110): the Stabilization of the Molecular Species. Surf. Sci. 2002, 512, 29-36. 
(41) Lindan, P.J.D. Water Chemistry at the SnO2(110) Surface: The role of Inter-molecular Interactions and Surface Geometry. Chem. Phys. Lett. 2000, 328, 325-329.

(42) Goniakowski, J.; Gillan, M.J. The Adsorption of $\mathrm{H} 2 \mathrm{O}$ on $\mathrm{TiO} 2$ and $\mathrm{SnO} 2(110)$ Studied By First-Principles Calculations. Surf. Sci. 1996, 350, 145-158.

(43) Santarossa, G.; Hahn, K.; Baiker, A. Free Energy And Electronic Properties Of Water Adsorption On The SnO2(110) Surface. Langmuir 2013, 29, 5487-5499.

(44) Kumar, N.; Kent, P.R.C.; Bandura, A.V.; Kubicki, J. D.; Wesolowski, D.J.; Cole, D. R.; Sofo, J.O. Faster Proton Transfer Dynamics of Water on SnO2 Compared to TiO2. J. Chem. Phys. 2011, 134, 044706.

(45) Xu, H.; Zhang, R.Q.; Ng, A.M.C.; Djurisic, A.B.; Chan, H.T.; Chan, W.K.; Tong, S.Y. Splitting Water on Metal Oxide Surfaces. J. Chem. Phys. C 2011, 115, 19710-19715.

(46) Wang, X.; Qin, H.; Chen, Y.; Hu, J. Sensing Mechanism of SnO2(110) Surface to CO: Density Functional Theory Calculations. J. Phys. Chem. C 2014, 118, 28548-28561.

(47) Diéguez, A.; Romano-Rodriguez, A.; Vilà, A.; Morante, J. R. The complete Raman spectrum of nanometric $\mathrm{SnO}_{2}$ particles. J. Appl. Phys., 2001, 90, 1550-1557.

(48) Liu, L. Z.; Li, T. H.; Wu, X. L.; Shen, J. C.; Chu, P. K. Identification of oxygen vacancy types from Raman spectra of $\mathrm{SnO}_{2}$ nanocrystals. J. Raman Spectrosc., 2012, 43, 1423-1426.

(49) Staerz, A.; Berthold, C.; Russ, T.; Wicker, S.; Weimar, U.; Barsan, N. The Oxidizing Effect of Humidity on WO3 Based Sensors. Sensors Actuators B 2016, 237, 54- 58. 


\section{TOC - Graphic}

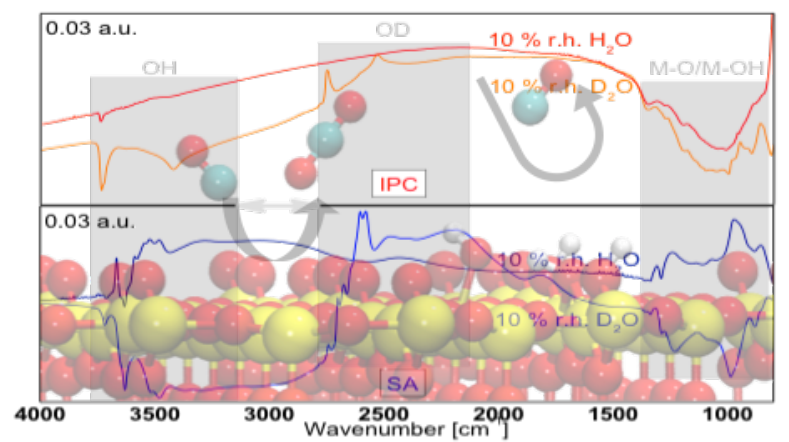

